\title{
Injection molding micro patterns with high aspect ratio using a polymeric flexible stamper
}

\author{
S. H. Park', W. I. Lee ${ }^{1 *}$, S. N. Moon ${ }^{1}$, Y.-E. Yoo ${ }^{2}$, Y. H. Cho \\ ${ }^{1}$ Division of WCU Multiscale Mechanical Design, Department of Mechanical and Aerospace Engineering, Seoul National \\ University, Seoul 151-742, Korea \\ ${ }^{2}$ Korea Institute of Machinery and Materials, Daejon 305-343, Korea \\ ${ }^{3}$ School of Mechanical Design \& Automation Engineering, Seoul National University of Technology, Seoul 139-743, \\ Korea
}

Received 21 February 2011; accepted in revised form 8 May 2011

\begin{abstract}
Poor filling occurs during the injection molding process of micro- or nano- scale patterns mainly because the hot polymer melt rapidly cools and its skin quickly solidifies upon contact with the mold surface. In this study, it is proposed to use Polyethylene terephthalate (PET) film coated with patterned polyurethane acrylate (PUA) as an effective thermal barrier. It can significantly hinder heat transfer into the mold during the molding process and thus may keep the melt viscosity low for longer duration. As a result, the replication would be improved not only during the filling phase but also during the packing phase. In order to verify the validity of the use of polymeric stamper, the melt-film interface temperature was evaluated by numerical simulation. Experimental results indicated that patterns possessing widths within the range of one to tens of micrometers and a height of approximately $10 \mu \mathrm{m}$ were successfully filled and demolded.
\end{abstract}

Keywords: processing technologies, micro-injection mold, flexible stamper

\section{Introduction}

In recent years, fabrication of polymer based micro components for optical and biomedical applications has gained increasing attention [1]. Micro-molding of polymer-based materials has the advantages of low cost, good biocompatibility, high optical clarity and high impact strength. Hot embossing and micro injection molding are the most industrially viable processes used for molding micro- and nano-patterns. The hot embossing process uses a pre-heated mold in an evacuated chamber, and is subsequently brought into contact with the thermoplastic polymer melt. After pressing the mold onto the polymer melt, the system that consists of the tool and part is cooled down, after which the part is demolded. The hot embossing process is suitable for replicating complex or high aspect ratio $(>2)$ microstructures
$[2,3]$. However, a major inconvenience encountered through this process is the need of long cycle times for heating and cooling both the mold and the material [4]. In comparison, micro injection molding possesses promising possibilities for mass production due to the short cycle time and the process ability to be easily automated. In this context, microinjection molding of polymer materials is a key technology for micro-and nano molding. With the existing injection molding equipment and techniques, complete replication of the micro- and submicron structures with aspect ratios larger than 2 are hard to obtain for various reasons [5]. In order to avoid incomplete filling of micro- and nano-patterns, the mold temperature should be near or higher than the softening temperature of the polymer during the filling and packing phases. This is due to the

\footnotetext{
${ }^{*}$ Corresponding author, e-mail: wilee@snu.ac.kr
}

(c) BME-PT 
fact that polymer melt above the glass transition temperature exhibits sufficient fluidity, and thus the polymer melt can adequately fill the sub-micron patterns before entering the glassy state. [6, 7]. As the aspect ratio increases, the mold temperature must also increase $[8,9]$. The variotherm system [10] can satisfactorily reach such temperatures without a dramatic increase in cycle time. However, this process ultimately reduces the mold lifetime [11] and demands expensive tools. Liou and Suh [12] proposed an insulated mold insert that was coated with Teflon for retaining the heat in the mold cavity. Kim et al. [13] introduced nano-pattern insert molding (NPIM) in which the nano-pattern is molded using the poly(vinly alcohol) (PVA) template film with nano-patterns on its surface. The temperature near the mold surface would be maintained above no-flow temperature for a relatively long duration by the polymeric stamper or coating material that acted as a thermal barrier, inevitably delaying the solidification of the polymer near the mold surface. As a result, transcription would be continued during the packing phase improving the quality of replication. Recently, polymeric stampers using PDMS have also been used for hot embossing due to their economic and straightforward approach to fabricate micro feature [14].
This study demonstrated the viability of a method to use polymeric film as a stamper for injection molding of micro patterns with a high aspect ratio $(>9)$. The polymeric stamper patterned with polyurethane acrylate (PUA) on the surface effectively delayed solidification near the mold surface. PUA resin used in this study is an ultra-violet (UV)curable polymer and forms cross-links after cure. Therefore, the polymeric stamper using the PUA does not have a melting temperature. In addition to the thermal stability, PUA is a Rigiflex polymer that possesses relatively high rigidity ( $>40 \mathrm{MPa})$ compared to PDMS and has low surface energy.

The effects of the polymeric stamper on the temperature profiles of the polymer melt and cavity surface were analyzed using commercial software Moldex3D. In order to verify the effect of the packing pressure and packing time on the transcription during the delayed solidification provided by the polymeric stamper, we fabricated micro-patterns that have a width within the range of one to tens of micrometers with a height of approximately $10 \mu \mathrm{m}$.

\section{Experiment and heat transfer analysis \\ 2.1. Fabrication of polymeric stamper}

The polymeric stamper was prepared using polyethylene terephthalate (PET) film as a substrate with

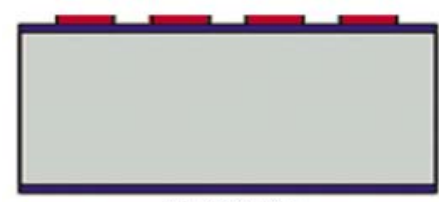

(a) $\mathrm{Si}_{3} \mathrm{~N}_{4} /$ litho

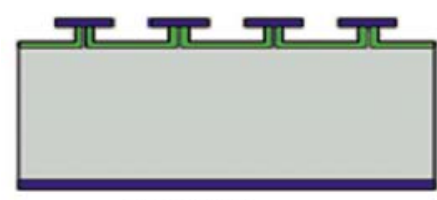

(d) LOCOS

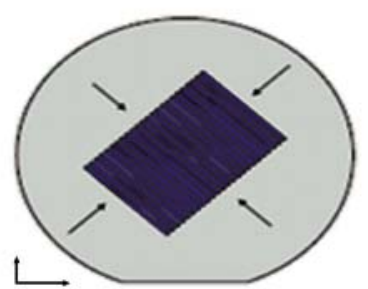

(g)

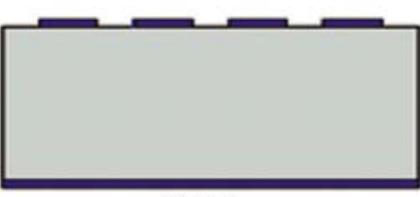

(b) RIE

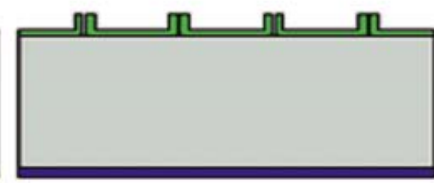

(e) RIE/dep-RIE

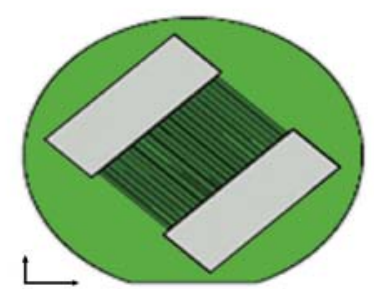

(h)

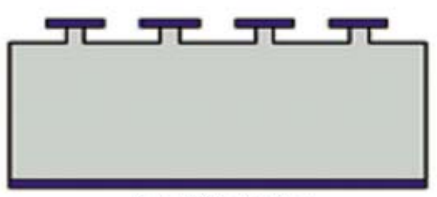

(c) $\mathrm{KOH}$ etching

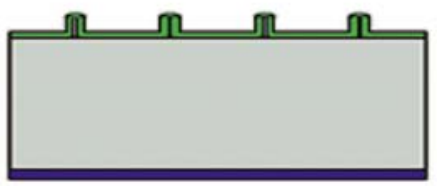

(f) Sputtering

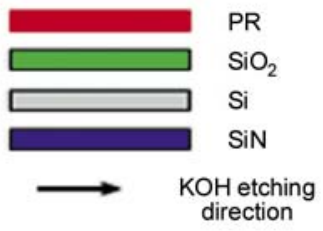

PR

$\mathrm{SiO}_{2}$

Si
direction

Figure 1. Illustration of silicon master fabrication process. (a) $\mathrm{Si}_{3} \mathrm{~N}_{4}$ deposition and photolithography. (b) RIE. (c) Anisotropic KOH etching. Si is vertically etched. (d) LOCOS. (e) RIE for removal of $\mathrm{Si}_{3} \mathrm{~N}_{4}$ mask and RIE or deep-RIE for Si etching. (f) Dioxide layer deposition for sealing. (g) Illustration showing the top side view of anisotropic $\mathrm{KOH}$ etching. (h) Schematic view of microchambers at the end of nanochannel arrays. 
PUA forming micro-patterns on the film surface. First, a silicon master to imprint the micro pattern was fabricated. The fabrication process comprises a combination of anisotropic etching, the local oxidation of silicon and the plasma etching of silicon
[15]. Figure 1 shows the fabrication process of the silicon master using a 3 -inch $<100>$ oriented single crystalline silicon wafer.

Once the silicon master is ready, the polymeric stamper was prepared by imprinting micro pattern

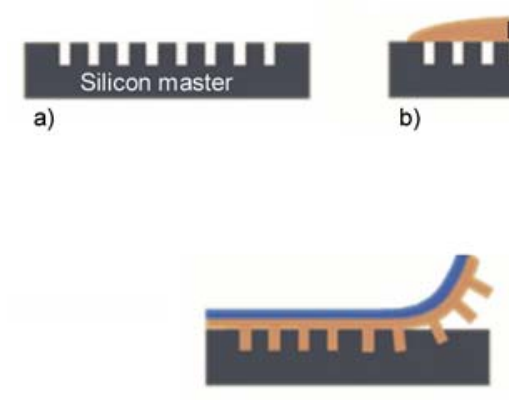

e)

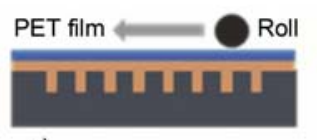

c)

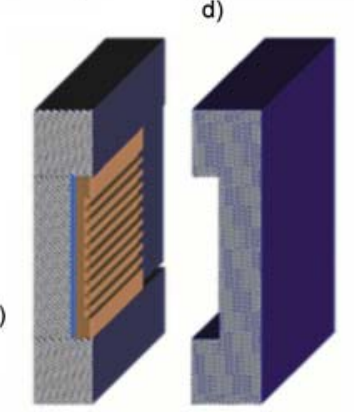

Figure 2. Illustration of fabrication process of flexible polymeric stamper and its installation on the mold wall. (a) Silicon master is prepared. (b) PUA is dispensed on the silicon master. (c) PET film is pressed against the silicon master with liquid PUA resin dispensed. (d) PUA resin is cured by irradiating ultraviolet light. (e) Pet film with PUA micro pattern on the surface (polymeric stamper) is detached from the silicon master. (f) Polymeric stamper is ready. (g) Polymeric stamper is attached on the mold wall.

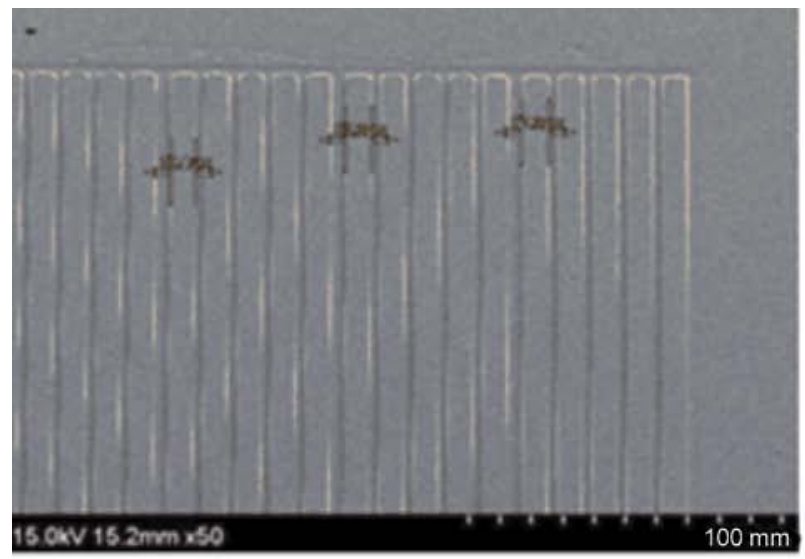

a)

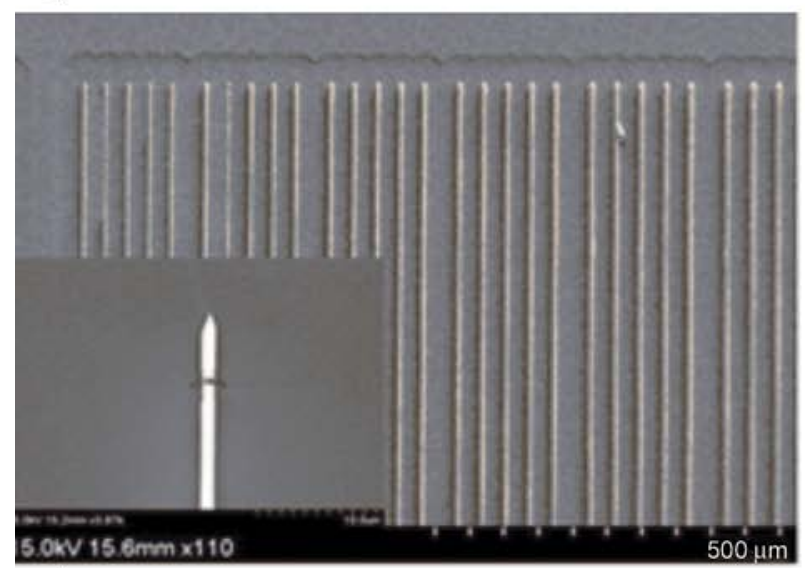

c)

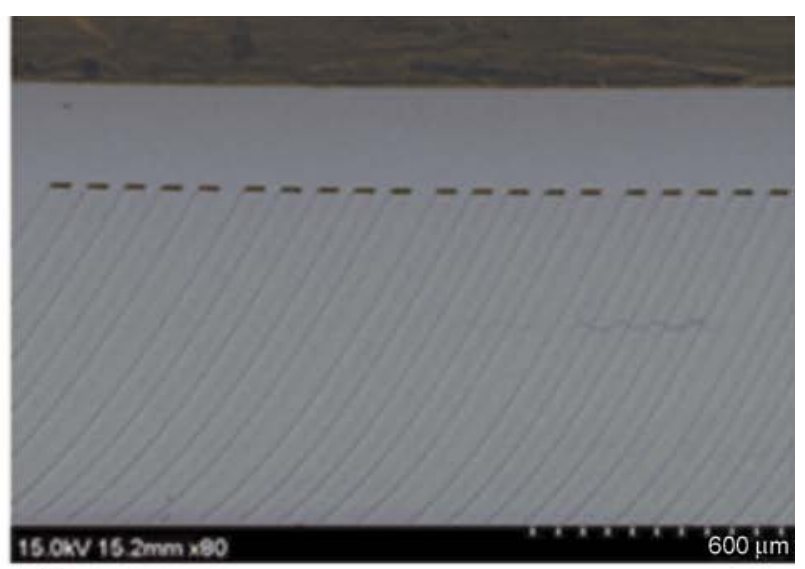

b)

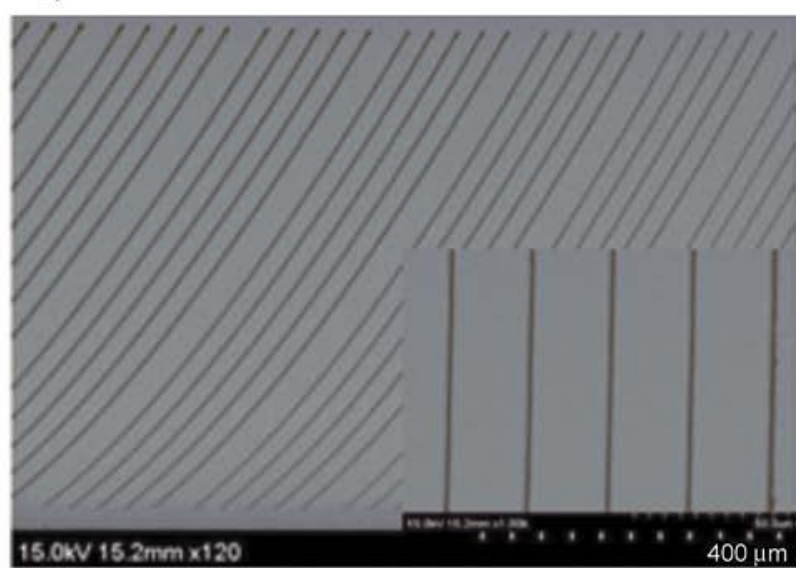

d)

Figure 3. The SEM surface image of the silicon master patterns and replicated PUA patterns. The pattern widths are about $90 \mu \mathrm{m}(\mathrm{a}$ and $\mathrm{b})$ and about $1 \mu \mathrm{m}$ ( $\mathrm{c}$ and $\mathrm{d}$ ). The height of the patterns is $10 \mu \mathrm{m}$ 
of PUA resin using the silicon master on PET film. As illustrated in Figure 2, PUA (MINS 311RM, Minuta Tech, Korea) resin was dispensed on the silicon master. The silicon master was composed of lines structure of varying channel widths, between 80 and $1.0 \mu \mathrm{m}$, with a channel depth of $10 \mu \mathrm{m}$ (Figure 2a). Once the photocurable PUA was drop-dispensed onto a master pattern (Figure 2b), a flexible $50 \mu \mathrm{m}$ thick PET film was pressed against the liquid drop (Figure 2c). A roller was used to distribute the resin evenly. The film was then exposed to ultraviolet light (wavelength: $250 \sim 356 \mathrm{~nm}$ ) for 4 minutes, at an intensity of $90 \mathrm{~mW} / \mathrm{cm}^{2}$ (Figure $2 \mathrm{~d}$ ). After UV curing, the fabricated stamper was peeled off from the master using tweezers (Figure 2e). The patterned stamper thus prepared was installed on one side of the injection mold cavity (Figure 2f).

Different micro patterns were used in this study as shown in Figure 3. Above mentioned technique allowed self-replication of the mold even for very fine patterns (less than $100 \mathrm{~nm}$ ) with high aspect ratio. The scanning electron microscopic (SEM) micrographs are presented in Figures $3 a$ and $3 c$ for the master and Figures $3 b$ and $3 d$ for the replicated patterns with PUA. These micrographs demonstrate the replication capability of the proposed method for various pattern widths and aspect ratios.

\subsection{Replication by injection molding}

The injection molded plate used in this study was rectangular in shape having dimensions of $60.0 \mathrm{~mm} \times$ $60.0 \mathrm{~mm} \times 1.0 \mathrm{~mm}$. Polymethylmethacrylate (PMMA) was injected into the cavity using an injection
Table 1. Injection molding process parameters

\begin{tabular}{|l|c|}
\hline Mold temperature $\left[{ }^{\circ} \mathrm{C}\right]$ & 25 \\
\hline Melt temperature $\left[{ }^{\circ} \mathrm{C}\right]$ & 265 \\
\hline Injection speed $[\mathrm{mm} / \mathrm{s}]$ & 250 \\
\hline Packing time $[\mathrm{s}]$ & $0.5,2$ \\
\hline Packing pressure $[\mathrm{MPa}]$ & $5,10,40$ \\
\hline Filling time $[\mathrm{s}]$ & 0.09 \\
\hline
\end{tabular}

molding machine (SE150 by Sumimoto). The injection molding conditions are listed in Table 1 . The injection speed, filling time, and melt temperature were set to $250 \mathrm{~mm} / \mathrm{s}, 0.09 \mathrm{~s}$ and $265^{\circ} \mathrm{C}$, respectively. In addition, three different packing pressures were selected and two different packing times were considered to see the effect of these parameters. The above mentioned molding conditions were chosen to evaluate the quality of transcription for cases in which the patterns were less than $4 \mu \mathrm{m}$. Patterns with channel width greater than $5 \mu \mathrm{m}$ were completely filled for the packing pressure above $5 \mathrm{MPa}$ and the packing time of $0.5 \mathrm{~s}$ (Figure 4).

The replication of the micro pattern was quantified using the ratio between the micro pattern depth and the filling depth. The degree of transcription (DOT) was defined as Equation (1):

$D O T=\frac{h_{\mathrm{f}}}{h_{\mathrm{m}}}$

where $h_{\mathrm{f}}$ is the depth of filling and $h_{\mathrm{m}}$ is the depth of the pattern in the stamper.

It is noted that the polymeric stampers lasted more than 100 injections for the patterning without causing significant deformation. Investigations of replicated polymer surfaces by SEM and atomic force microscopy (AFM) provided no evidence for abra-

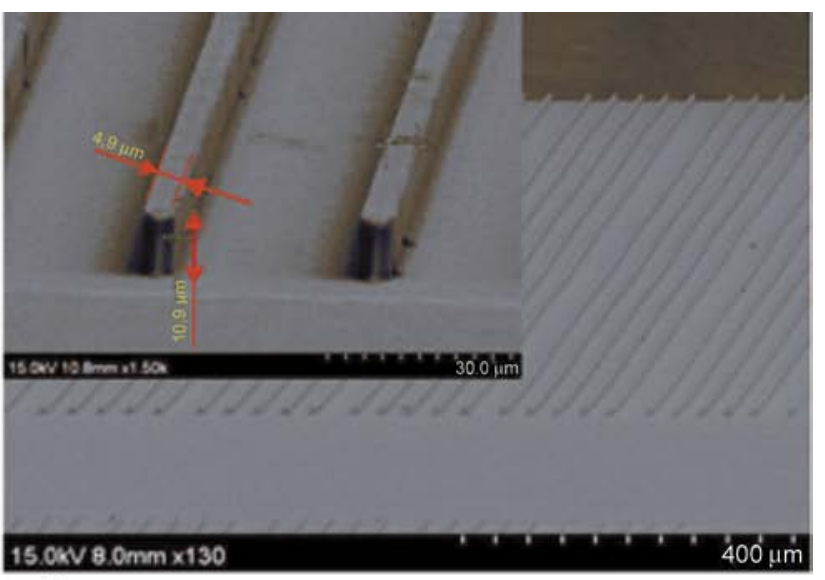

b)

Figure 4. SEM image of the replicated pattern. Packing time was $0.5 \mathrm{~s}$ and packing pressure was $40 \mathrm{MPa}$ : (a) Pattern with low aspect ratio; (b) pattern with high aspect ratio. 
sion residues of the PUA master on the polymer surface.

\subsection{Numerical analysis of temperature}

In order to investigate further the effectiveness of the polymeric stamper as a thermal barrier, heat transfer analysis was done numerically. The injection molding analysis software Moldex3D was used to simulate the polymeric stamper effects on the temperature variation during injection molding by setting similar boundary and initial conditions to the real processes. During the mold filling in the injection molding, due to the thermal contact resistance between the mold and the melt, the mold-melt interface temperature $\left(T_{\mathrm{mt}}\right)$ is usually higher than the set mold temperature $\left(T_{\mathrm{mb}}\right)$. In many cases, however, $T_{\mathrm{mt}}$ may not be so different from $T_{\mathrm{mb}}[16]$. In this study, $T_{\mathrm{mb}}$ was used to represent $T_{\mathrm{mt}}$ in the molding simulations. In the simulations, initial mold temperatures and the resin temperature were set to be 30 and $265^{\circ} \mathrm{C}$, respectively. Various film thicknesses $(50,75$, and $100 \mu \mathrm{m})$ were also assumed for the simulations. Thermophysical properties used in the calculations are listed in Table 2.

For the energy equation, the boundary condition is defined as Equations (2) and (3):

$q=h_{\mathrm{c}}\left(T_{\mathrm{mt}}-T_{\mathrm{mb}}\right) \quad(z=p$, Figure 5$)$

$k_{\mathrm{m}}=\frac{\partial T_{\mathrm{m}}}{\partial z}=k_{\mathrm{f}} \frac{\partial T_{\mathrm{f}}}{\partial z} \quad(z=p+f$, Figure 5)

The heat transfer coefficient $h_{\mathrm{c}}$ between the part and mold base depends on materials, temperature, and process conditions. The default value in Moldex3D

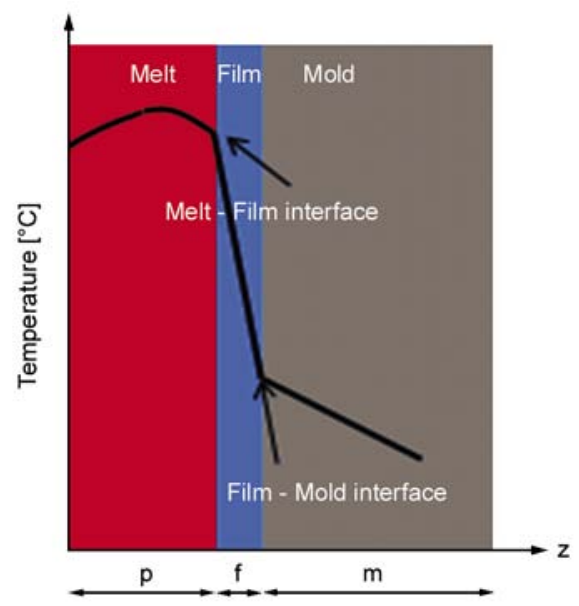

Figure 5. Illustration of temperature profiles with the polymeric stamper as a thermal barrier
Table 2. Thermophysical properties used for heat transfer anaysis

\begin{tabular}{|l|c|c|c|}
\hline & Mold (Steel) & PMMA & PET \\
\hline Density $\left[\mathrm{kg} / \mathrm{m}^{3}\right]$ & 7820 & 1160 & 1405 \\
\hline Thermal conductivity $\left[\mathrm{W} / \mathrm{m}^{\circ} \mathrm{C}\right]$ & 50.2 & 0.15 & 0.2745 \\
\hline Specific heat $\left[\mathrm{J} / \mathrm{kg}^{\circ} \mathrm{C}\right]$ & 485 & 2050 & 1924 \\
\hline
\end{tabular}

was used and the heat transfer coefficient in this study was $5000 \mathrm{~W} / \mathrm{m}^{2} \cdot \mathrm{K}$.

\section{Results and discussion}

\subsection{Heat transfer analysis}

The influence of the polymeric stamper on heat transfer is identified by comparing the rate of temperature increase on the mold surface with and without the polymeric stamper and shows the effect of PET film thickness (Figure 6). For conventional injection molding, mold surface temperature rapidly rises when the melt contacts the mold surface during the filling phase. For the case in which the polymeric stamper is used, it retards heat flow into the mold surface, resulting in a slower rise in the mold surface temperature. As a result, the temperature of the polymer near the polymeric stamper surface was maintained above no-flow temperature for longer duration than the conventional injection molding process, as shown in Figure 7 and Figure 8. Because the viscosity is a function of temperature, the fluidity of the polymer melt improved markedly. Also, the fluidity was maintained for a relatively longer period of time. This improvement indicates that the polymer melt near the polymeric stamper easily flows into the micro patterns even during the packing phase as well as the filling phase.

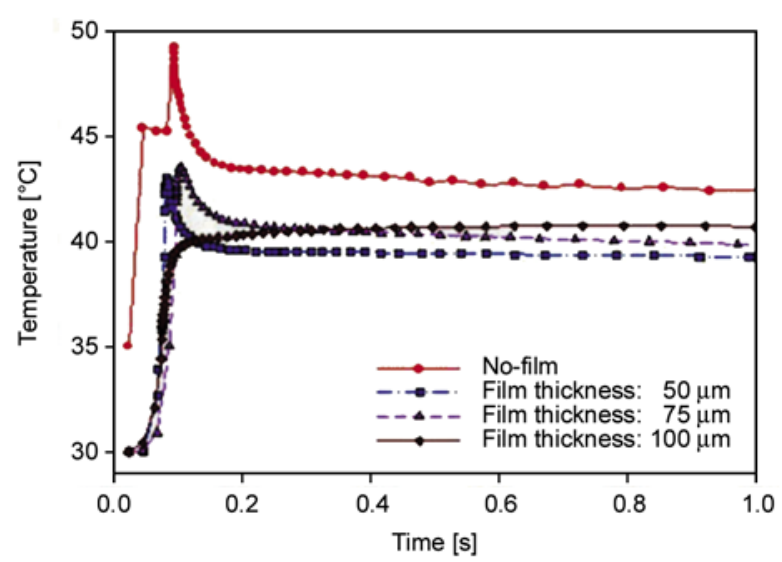

Figure 6. Change in mold cavity surface temperature with time. Comparison of numerical results with and without polymeric stamper. 

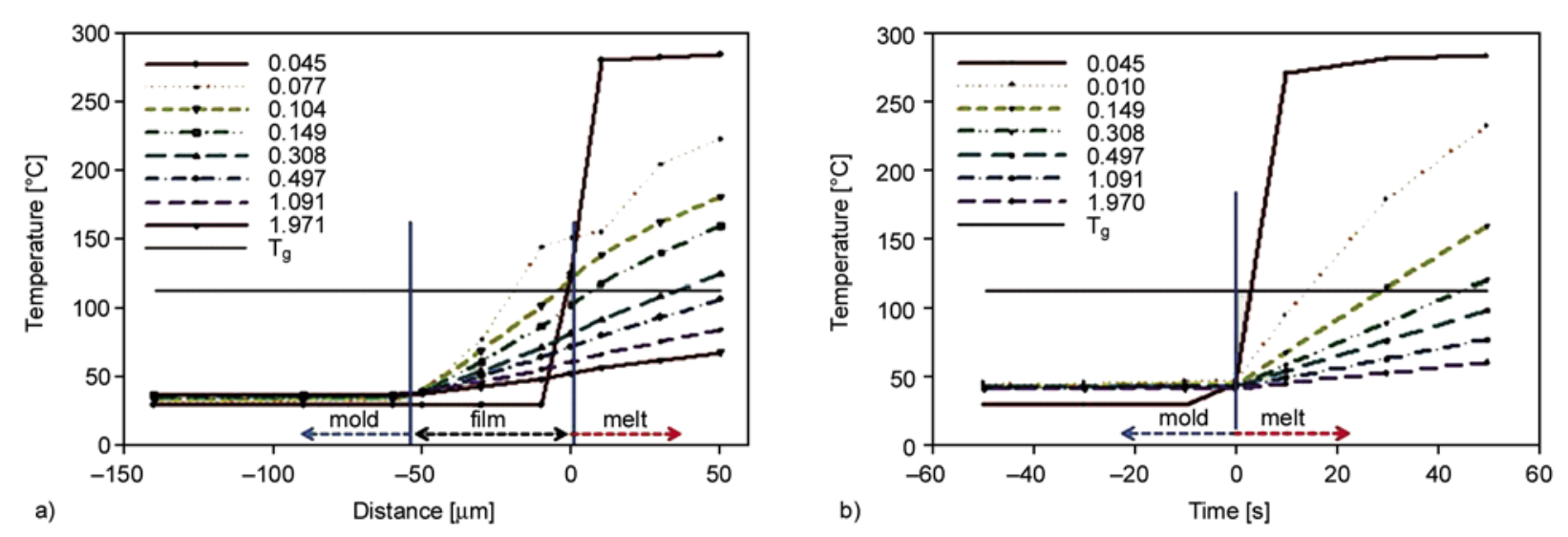

Figure 7. Temperature profile near the polymeric stamper right after contact with the melt ( 0.01 to $2.0 \mathrm{~s}$ after the contact): (a) with $50 \mu \mathrm{m}$ thickness polymeric stamper, (b) without polymeric stamper. Results of numerical simulation

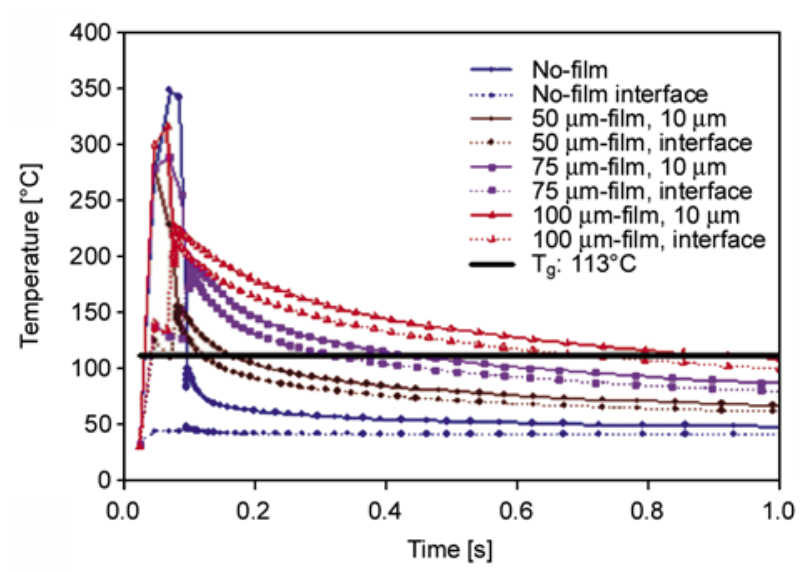

Figure 8. Temperature profile near the polymeric stamper (10 $\mu \mathrm{m}$ from the mold or polymer stamper) and in the interface between mold and melt right after contact with the melt $(0.01$ to $1.0 \mathrm{~s}$ after the contact). Results of numerical simulation.

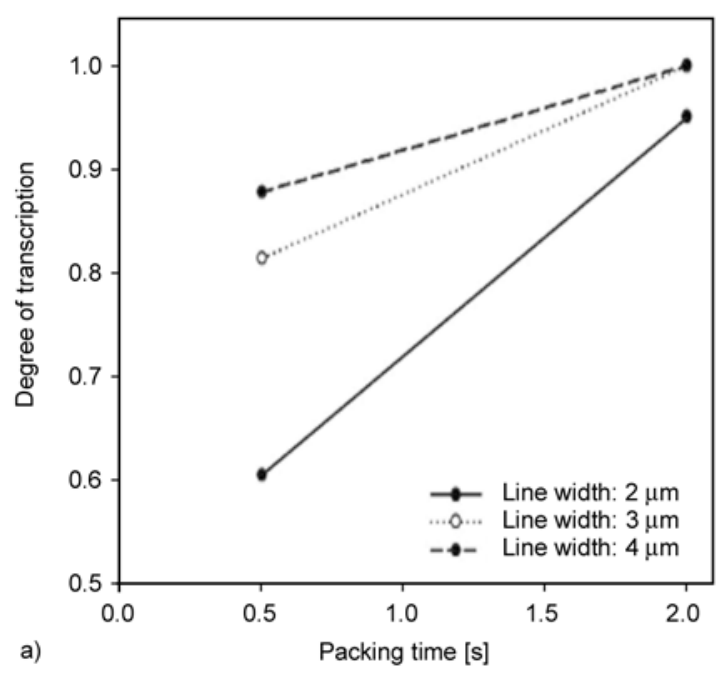

\subsection{Effect of the packing pressure and packing time}

A key to better transcription of micro patterns during injection molding would be high fluidity of the melt especially near the mold wall where the micro patterns are located. The parameters related to fluidity of the melt would be, among others, the injection velocity and the melt temperature, and the mold temperature. At higher melt temperature, the polymer flows longer because of lower viscosity of the melt and thus the degree of transcription and pattern definition will be improved. Higher injection velocity also reduces cooling of the melt during filling, and thus, improves pattern replication. While higher mold temperatures will slow the cooling and allow more melt to flow into the micro patterns, the mold temperature significantly affects how the packing pressure and packing time influ-

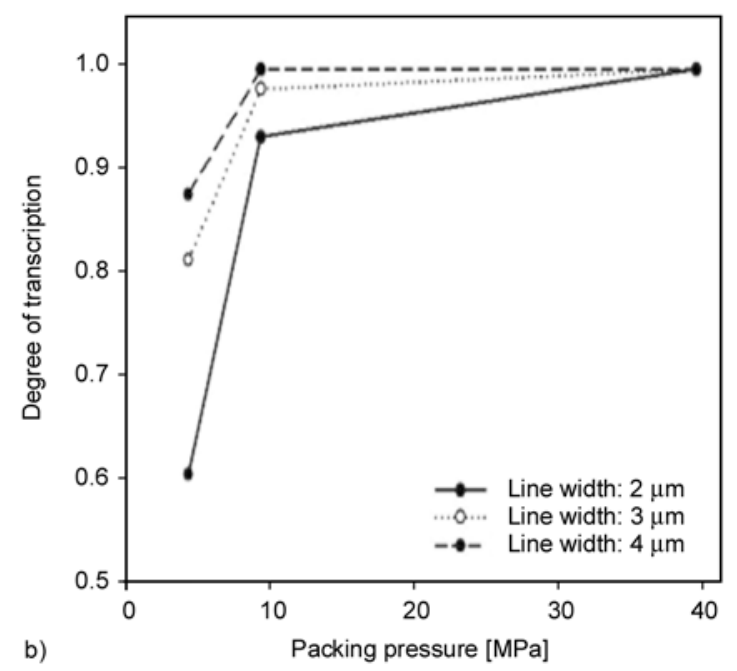

Figure 9. Effect of the packing pressure and the packing time on the degree of transcription. Experimental data. (a) Degree of transcription in relation to the packing time for the packing pressure of $5 \mathrm{MPa}$. (b) Degree of transcription in relation to the packing pressure for the packing time of $0.5 \mathrm{~s}$. 


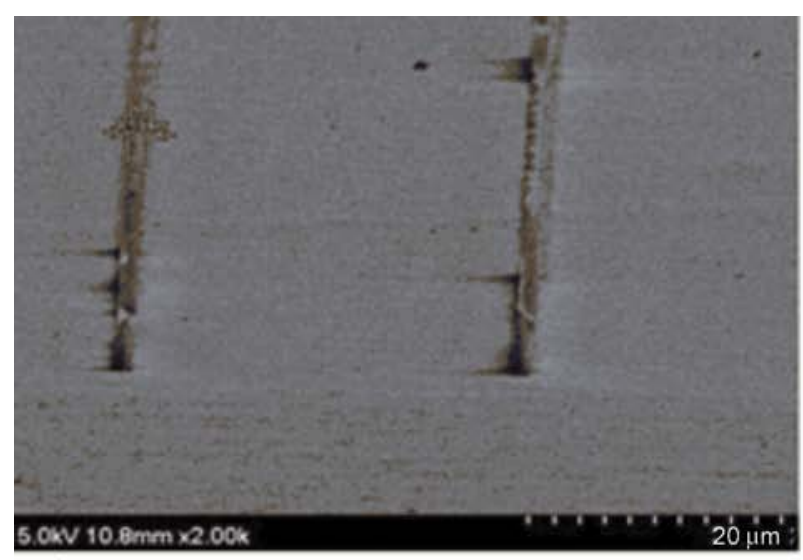

a)

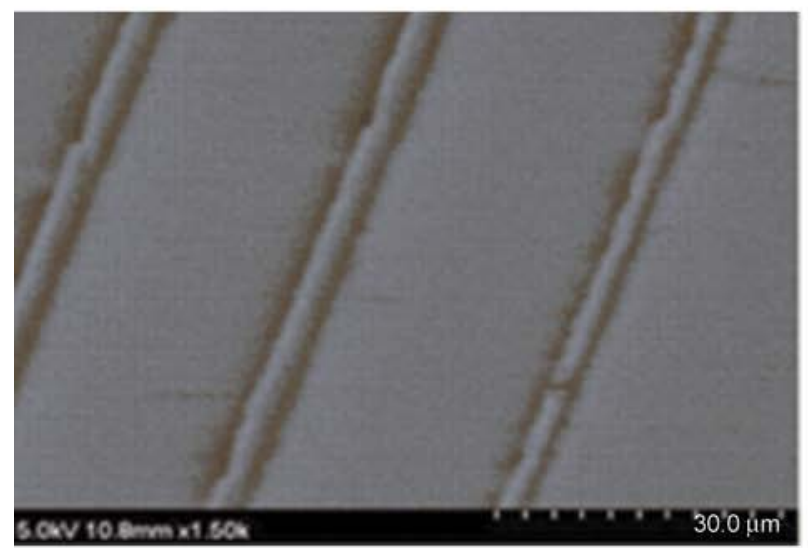

c)

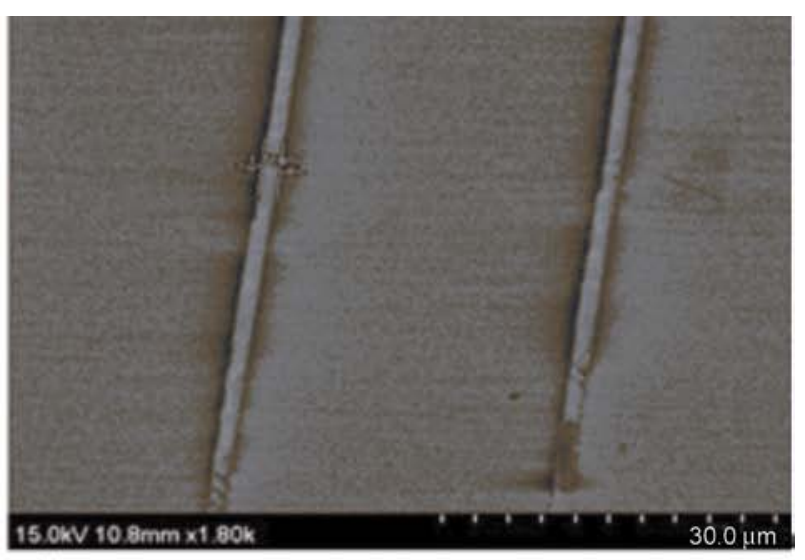

b)

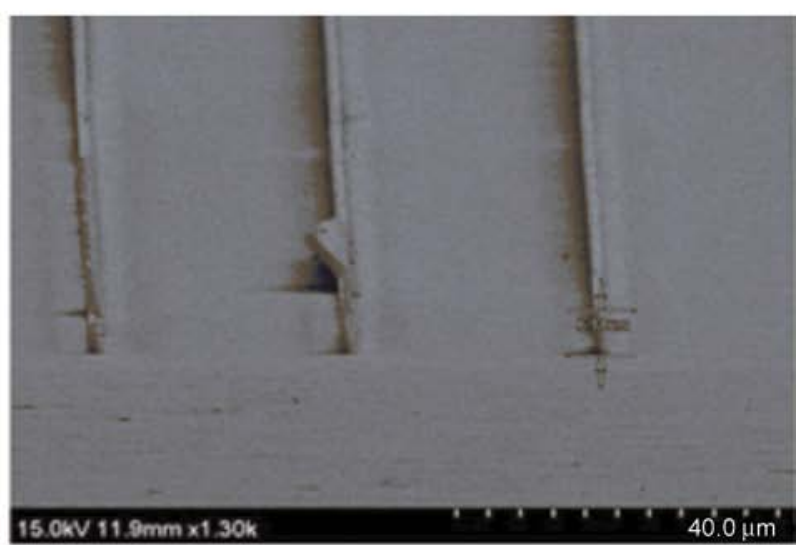

d)

Figure 10. SEM image of the replicated patterns under various packing pressures and times pattern width of $1 \mu \mathrm{m}$. As can be seen, replication quality was not consistent $(\mathrm{a}-\mathrm{d})$.

ences the transcription [17]. For cases in which the mold temperature is low, packing pressure and packing time do not significantly influence the filling depth in comparison to other conditions. It is because the solidified layer near the mold wall prevents polymer melt from flowing into the micro patterns. As a result, if the temperature of the polymer near the stamper surface is maintained above the no-flow temperature for a long period of time, packing pressure would improve the transcription.

The relationship between transcription and the packing time is shown in Figure 9a. While the packing pressure was maintained, the degree of transcription increased. The degree of transcription in relation to the packing pressure is shown in Figure $9 \mathrm{~b}$. As the packing pressure increased from 5 to $40 \mathrm{MPa}$, micro-patterns were completely replicated without increasing the packing time. In addition, the patterns with larger line-width were completely filled at lower packing pressure and packing time. For patterns with width less than $1 \mu \mathrm{m}$, replication

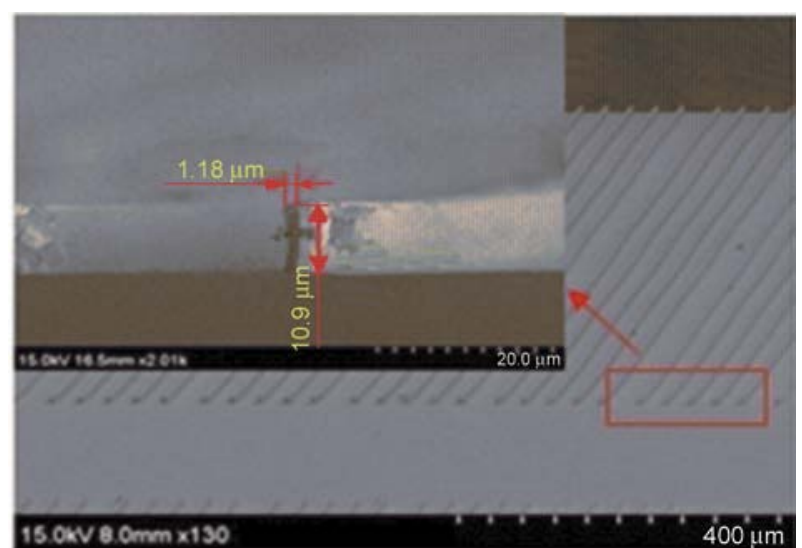

Figure 11. SEM image of the replicated pattern with high aspect ratio of 9.24.

quality was not consistent as can be seen from Figure 10. In summary, at relatively high packing pressure $(40 \mathrm{MPa})$ and long packing time $(5 \mathrm{~s})$, micro patterns with narrow line width (down to about $1 \mu \mathrm{m}$ ) and high aspect ratio (above 9) was successfully replicated (Figure 11). 


\section{Conclusions}

This study demonstrates the viability to fabricate micro patterns with high aspect ratios ( $>9)$ using the polymeric stamper patterned with PUA on the surface. The silicon master was made with a novel fabrication technique for generating silicon dioxide channel arrays without the use of the nanolithography technique and polymeric stamper was used instead of the nickel mold insert. The temperature of the polymer melt near the polymeric stamper surface was maintained above the no-flow temperature for a longer duration in comparison to conventional injection molding. As a result, delaying the development of the solidified layer and increasing the fluidity of the polymer melt during the packing phase as well as the filling phase near the stamper surface improved the transcription quality for patterns with a high aspect ratio $(>9)$. The life of the polymer stamper well exceeded 100 cycles, which suggest a possibility of practical application. Compared with conventional hard masters, durability can be an issue for polymeric molds used in this study. In order for the proposed method to be used in the applications with high production runs, durability of the polymer stampers should be investigated thoroughly.

Another important point is that the micro patterns with high aspect ratio were fabricated without fracture. The PUA mold used in this study had low surface energy. Because of these advantages, the polymer stamp using PUA had good demolding characteristics and releasing the polymer from the stamper was easy.

\section{Acknowledgements}

This work was supported by the Korea Research Foundation Grant funded by the Korean Government (MOEHRD) (Grant KRF-J03003) and by WCU (World Class University) program (R31-2008-000-10083-0).

\section{References}

[1] Weber L., Ehrfeld W., Freimuth H., Lacher M., Lehr H., Pech B.: Micromolding: A powerful tool for largescale production of precise microstructures. in 'Proceedings of the SPIE 2879, Austin, USA' 156-167 (1996).

DOI: $10.1117 / 12.251203$
[2] Becker H., Heim U.: Hot embossing as a method for the fabrication of polymer high aspect ratio structures. Sensors and Actuators A: Physical, 83, 130-135 (2000). DOI: $10.1016 / \mathrm{S} 0924-4247(00) 00296-X$

[3] Mekaru H., Yamada T., Yan S., Hattori T.: Microfabrication by hot embossing and injection molding at LASTI. Microsystem Technologies, 10, 682-688 (2004).

DOI: $10.1007 / \mathrm{s} 00542-004-0401-8$

[4] Heckele M., Schomburg W.: Review on micro molding of thermoplastic polymers. Journal of Micromechanics and Microengineering, 14, 1-14 (2004). DOI: $10.1088 / 0960-1317 / 14 / 3 /$ R01

[5] Mönkkönen K., Pakkanen T. T., Hietala J., Pääkkönen E. J., Pääkkönen P., Jääskeläinen T., Kaikuranta T.: Replication of sub-micron features using amorphous thermoplastics. Polymer Engineering and Science, 42, 1600-1608 (2002).

DOI: $10.1002 /$ pen.11055

[6] Ong N. S., Koh Y. H.: Experimental investigation into micro injection molding of plastic parts. Materials and Manufacturing Processes, 20, 245-253 (2005). DOI: 10.1081/AMP-200042004

[7] Su Y-C., Shah J., Lin L.: Implementation and analysis of polymeric microstructure replication by micro injection molding. Journal of Micromechanics and Microengineering, 14, 415-422 (2004). DOI: $10.1088 / 0960-1317 / 14 / 3 / 015$

[8] Whiteside B. R., Martyn M. T., Coates P. D., Allan P. S., Hornsby P. R., Greenway G.: Micromoulding: Process characteristics and product properties. Plastics, Rubber and Composites, 32, 231-239 (2003). DOI: $10.1179 / 146580103225002650$

[9] Whiteside B. R., Martyn M. T., Coates P. D., Greenway G., Allen P., Hornsby P.: Micromoulding: Process measurements, product morphology and properties. Plastics, Rubber and Composites, 33, 11-17 (2004). DOI: $10.1179 / 146580104225018346$

[10] Chang P-C., Hwang S-J.: Simulation of infrared rapid surface heating for injection molding. International Journal of Heat and Mass Transfer, 49, 3846-3854 (2006).

DOI: 10.1016/j.ijheatmasstransfer.2006.04.014

[11] Tseng S-C., Chen Y-C., Kuo C-L., Shew B-Y.: A study of integration of LIGA and M-EDM technology on the microinjection molding of ink-jet printers' nozzle plates. Microsystem Technologies, 12, 116-119 (2005). DOI: $10.1007 / \mathrm{s} 00542-005-0014-\mathrm{x}$

[12] Liou M. J., Suh N. P.: Reducing residual stresses in molded parts. Polymer Engineering and Science, 29, 441-447 (1989). DOI: $10.1002 /$ pen.760290703

[13] Kim S. H., Jeong J. H., Youn J. R.: Nanopattern insert molding. Nanotechnology, 21, 205302/1-205302/6 (2010). DOI: $10.1088 / 0957-4484 / 21 / 20 / 205302$ 
[14] Malek C. K., Coudevylle J-R., Jeannot J-C., Duffait R.: Revisiting mic ro hot-embossing with moulds in non-conventional materials. Microsystem Technologies, 13, 475-481 (2007).

DOI: 10.1007/s00542-006-0184-1

[15] Cho Y. H., Lee S. W., Kim B. J., Fujii T.: Fabrication of silicon dioxide submicron channels without nanolithography for single biomolecule detection. Nanotechnology, 18, 465303/1-465303/6 (2007).

DOI: $10.1088 / 0957-4484 / 18 / 46 / 465303$
[16] CoreTech System Co. Ltd.: Moldex3D/solid-RIM reference manual. HsinChu, Taiwan (2003).

[17] Lee B-K., Hwang C-J.: Replication quality of flowthrough microfilters in microfluidic lab-on-a-chip for blood typing by microinjection molding. Journal of Manufacturing Science and Engineering, 130, 021010/1-021010/8 (2008).

DOI: $10.1115 / 1.2896142$ 